\title{
LA ARQUEOFAUNA DEL CAMPO VOLCÁNICO PALI AIKE. EL SITIO OREJAS DE BURRO 1, SANTA CRUZ, ARGENTINA
}

G. LORENA L'HEUREUX*

Recibido: 01/01/2008

Aceptado: 23/05/2008

\section{RESUMEN}

El objetivo de este trabajo es presentar el análisis arqueofaunístico del conjunto de materiales recuperados en el sitio Orejas de Burro 1 (OB1), sector meridional del campo de lava Pali Aike (CVPA) -Santa Cruz, Argentina-. Se analizaron dos sectores excavados de forma independiente, uno correspondiente a un área de entierro situada hacia el fondo de la cueva y otro a un sondeo realizado en un espacio no alterado antropicamente contiguo al enterratorio. Desde un punto de vista temporal, se separaron dos conjuntos correspondientes al Holoceno tardío inicial (ca. 3.500 años ${ }^{14} \mathrm{C}$ AP) y al Holoceno tardío final (ca. $1.700-500$ años ${ }^{14} \mathrm{C}$ AP). Los resultados obtenidos mostraron diferencias significativas en la representación de variables tafonómicas y de frecuencias y diversidad de especies por sectores excavados y por bloques temporales. En particular, se evidencia un uso más intenso de la cueva hacia el 3.500 años AP, coincidiendo con una mayor representación de especies procedentes de la costa del estrecho de Magallanes (moluscos; aves de ambiente marino/costero), las cuales habrían sido explotadas en el marco de movimientos logísticos por parte de grupos cazadores del interior.

PALABRAS CLAVES: arqueofauna; cazadores-recolectores; Pali Aike; Holoceno tardío.

\section{THE ARCHAEOFAUNAL RECORD OF THE PALI AIKE LAVA FIELD. THE OREJAS DE BURRO 1 SITE, SANTA CRUZ PROVINCE, ARGENTINA.}

\begin{abstract}
The aim of this paper is to present the results of the archaeofaunal analysis carried out on bone materials recovered at the Orejas de Burro archaeological site (OB1), in the Pali Aike lava field ("CVPA"), Santa Cruz, Argentina. Two independently excavated sectors were considered, one corresponding to a burial area located at the bottom of the cave, and the other one corresponding to a test pit placed next to the burial area. Chronologically, two assemblages were identified, the first one corresponding to the early Late Holocene (ca. $3.500{ }^{14} \mathrm{C}$ years $\mathrm{BP}$ ), and the second one to the later Late Holocene (ca. 1.700-500 años ${ }^{14} \mathrm{C} \mathrm{AP)}$. The obtained results show statistically significant differences in the manifestation of taphonomic variables and in the frequency and diversity of faunal species both, spatially and temporally. In particular, a more intensive use of the cave at around $3.500{ }^{14} \mathrm{C}$ years $\mathrm{BP}$ is inferred, coincidental with a higher representativeness of coastal taxa like mollusk and sea/coastal birds. Such species may have been exploited during logistic movements to the Magellan strait carried out by hunter gatherers from the inland.
\end{abstract}

KEY WORDS: archaeofaunal record; hunter-gatherer; Pali Aike; Late Holocene.

* DIPA-IMHICIHU (CONICET). Saavedra 15, 5oiso (1083 ACA). Buenos Aires, Argentina. E-mail: lorenalheureux@yahoo. com.ar 


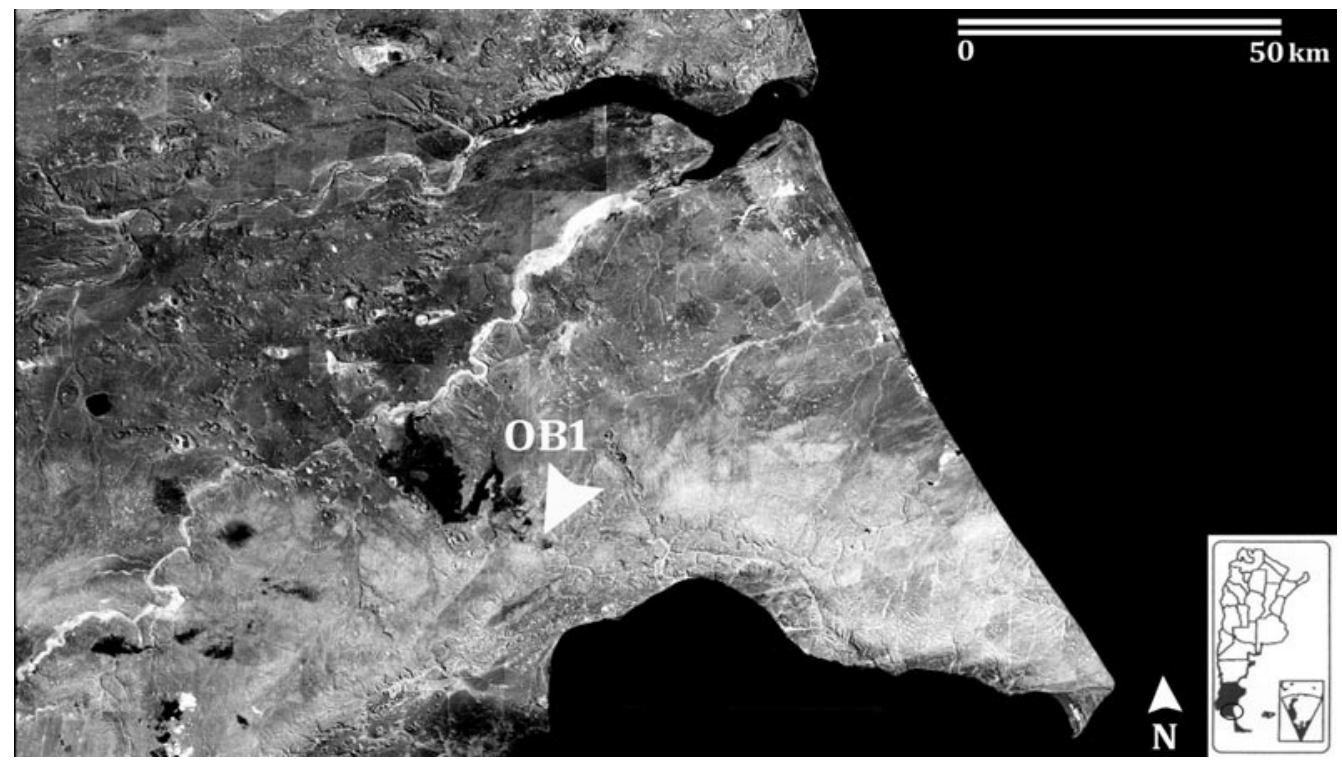

Fig. 1. El Campo Volcánico Pali Aike. Localización del sitio Orejas de Burro 1.

\section{EL SITIO OREJAS DE BURRO 1}

El sitio Orejas de Burro 1 (OB1), se ubica en el sector argentino del campo volcánico Pali Aike (CVPA), provincia de Santa Cruz (52웅.769' S, 69 33.151' W; Fig. 1), en una cueva localizada en la ladera interna del sector sur del cono volcánico homónimo. Este cono forma parte de la unidad volcánica 2 del campo de lava Pali Aike, originado entre 2.1 millones de años y 300.000 años AP (D'Orazio et al. 2000). La boca de esta cueva basáltica se orienta al noroeste y tiene aproximadamente $12 \mathrm{~m}$ de largo y $5 \mathrm{~m}$ de ancho.

Se conoce que en la década del ' 70 un grupo de aficionados realizó excavaciones en OB1 (Guerra de Fretes, 1977), recuperando un entierro de dos individuos. Esto se pudo verificar durante los primeros trabajos sistemáticos en el área (Borrero et al. 2004), cuando se localizó la cueva y en el centro de la misma un foso con forma circular. También se registraron montículos de sedimentos redepositados con abundantes restos de fauna en la entrada de la misma pertenecientes a aquellos removidos durante dicha intervención.

Al dar comienzo a los trabajos arqueológicos, desde una perspectiva exploratoria y poco invasiva, se realizó un sondeo de 0,25 $\mathrm{m} 2$ en un sector libre de bloques de derrumbe y próximo al área alterada mencionada. A los $95 \mathrm{~cm}$ de profundad en el

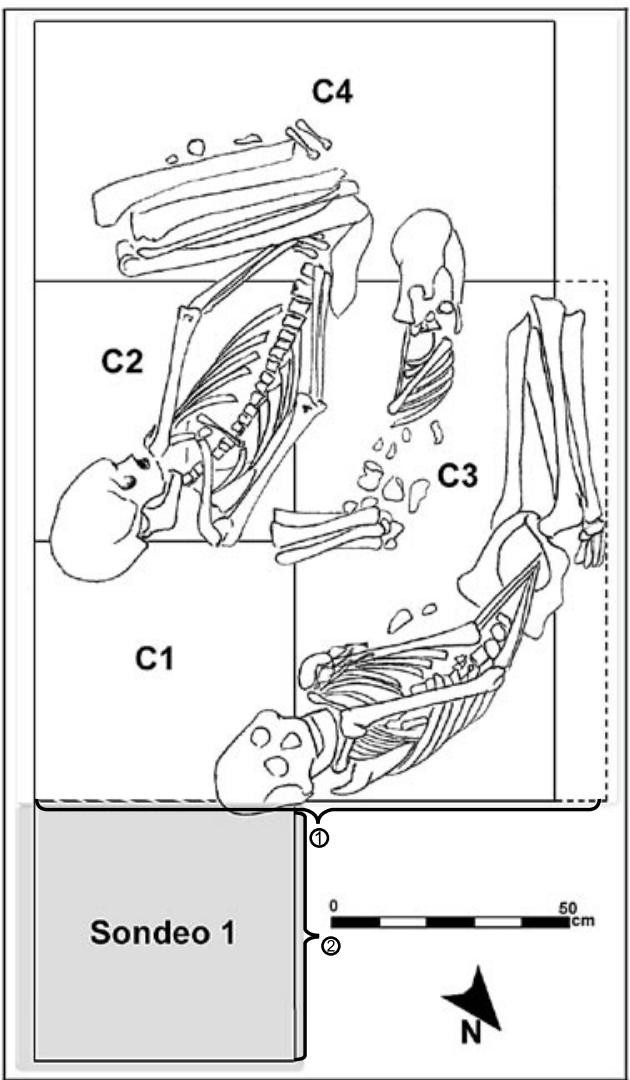

Fig. 2. Planta de las cuadrículas excavadas. 


\section{SONDEO 1}

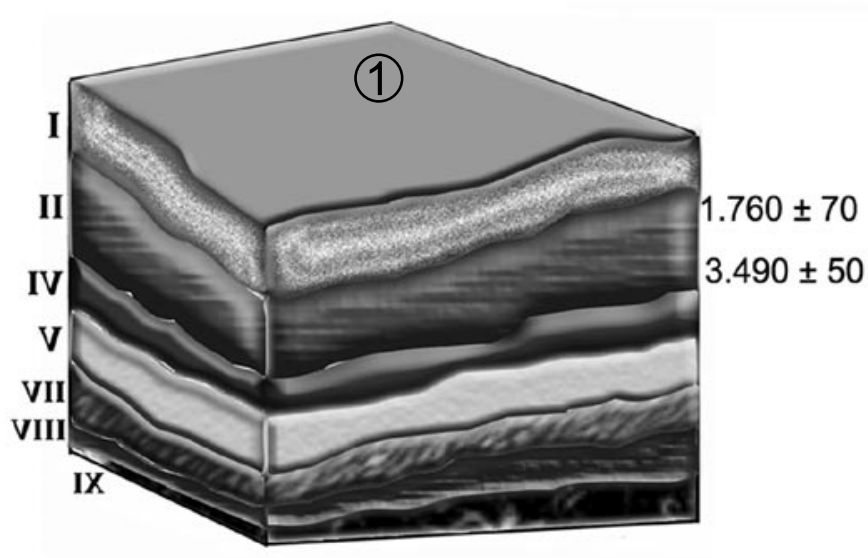

ÁREA DEL ENTIERRO

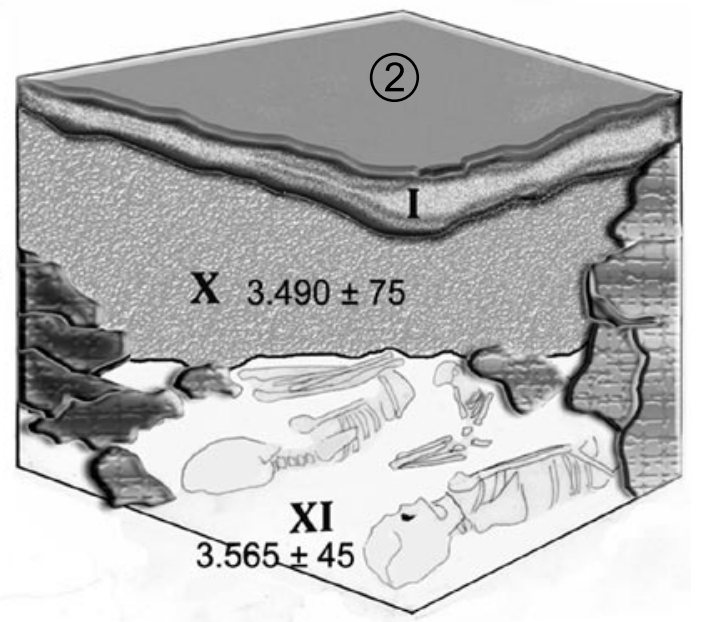

Fig. 3. Unidades estratigráficas representadas en el sector del sondeo y en el área del entierro.

perfil sur del sondeo se hizo contacto con un cráneo humano. A partir de este hallazgo, se planteó la excavación del entierro detectado, que resultó ser una inhumación sincrónica de cinco individuos diferencialmente representados de distintas categorías de edad: tres subadultos, un adulto joven y otro adulto mayor. Estos últimos de sexo probablemente masculino (L'Heureux y Barberena 2008).

Se abrieron cuatro cuadrículas de diferentes dimensiones contiguas al sondeo, las cuales fueron planteadas en función de la orientación y dimenciones de la estructura de entierro (Fig. 2). En total se excavaron $1,75 \mathrm{~m} 2$. En el sondeo 1 se reconocieron siete unidades extratigráficas (I; II; III/IV; V; VII; VIII y IX), y en el área del entierro tres unidades (I; X; XI) (Barberena et al. 2006). El sector del sondeo no forma parte de la estructura de entierro, que comieza en su perfil sur, por esto las unidades estratigráficas reconocidas en ambos sectores son diferentes, a excepción de la unidad I, que se trata de una capa de guano compactado (Fig. 3).

Lo que importa destacar es que la secuencia de las unidades observadas en los perfiles del sondeo desaparecen al interceptar el entierro. Se registra una abrupta interrupción en la continuidad de las unidades II a IX reconocidas, y aparecen otras dos de génesis antrópica que se asocian con la inhumación (unidades X y XI; Barberena 2008). La unidad XI $(70 / 75-90 \mathrm{~cm})$ es la matriz del entierro, y la unidad
$\mathrm{X}(38-70 / 75 \mathrm{~cm})$ el sedimento que lo cubre. Esta última representa un depósito artificial colocado para rellenar la fosa cavada intencionalmente para inhumar los esqueletos. El relleno estaba compuesto por una gran cantidad de restos de fauna, moluscos, algunos artefactos líticos y relativamente escaso sedimento, dando lugar a espacios vacíos y huesos entrampados entre los bloques de roca de caja que también formaban parte de esta unidad. Los especimenes de fauna se presentaban revueltos y desordenados, aunque se observaron casos de elementos enteros articulados (Fig. 4). La descripción sedimentológica y geomorfológica del sitio se presenta con detalle en otros trabajos (Barberena et al. 2006; Barberena 2008).

El sitio cuenta con seis dataciones radiocarbónicas (Tabla 1). Cuatro de ellas proceden de las unidades I y II del sondeo, y dos de las unidades X y XI del sector de la estructura de entierro. Uno de los esqueletos humanos (unidad XI) y un splinter de tibia de guanaco del relleno (unidad X) fueron datados en más de 3.500 años AP, obteniendo edades no distinguibles a nivel estadístico. Esto último respalda la contemporaneidad del enterratorio y del sedimento de relleno, el cual parece haberse formado con aportes de diferentes unidades colindantes (VII a IX; Barberena et al. 2006). Por otro lado, los fechados realizados sobre las valvas de Mytilus sp. procedentes del sondeo, ubican al sitio en momentos muy tardíos (Tabla 1). A su vez, estas edades tienen desvíos estándar muy 


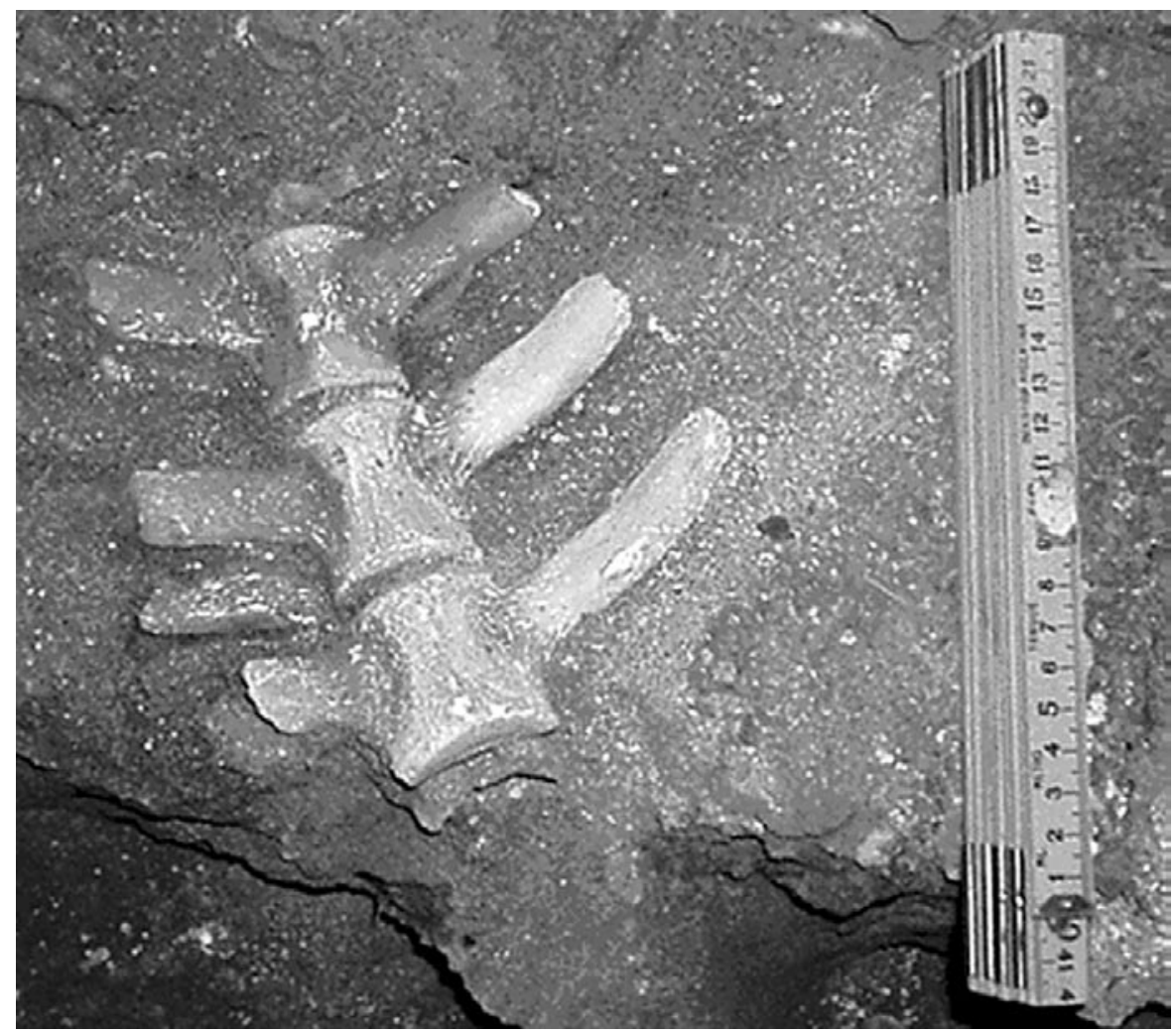

Fig. 4. Unidad estratigráfica X. En este depósito de origen antrópico se registraron elementos óseos de guanaco enteros articulados. Se observan rastros de $\mathrm{CaCO} 3$ en el sedimento y sobre

amplios y un efecto reservorio que se estima puede alcanzar hasta 400 años (Cordero et al. 2003).

De acuerdo con lo expuesto, en este trabajo se realiza un abordaje del análisis faunístico intra sitio espacial y temporal. Para el primero, se analizan de forma independiente el material procedente del sector del entierro (Cuadrículas 1 a 4: unidades I, $\mathrm{X}$ y XI) y del sondeo 1 (unidades I a IX), a pesar de representar espacialmente una única excavación. Esto se justifica, tal como fuera desarrollado supra, en que las unidades que comprenden estos sectores excavados representan contextos diferentes en su génesis y funcionalidad.

En cuanto a la aproximación temporal, se considera que en OB1 esta variable no presenta una alta resolución. Por esto, se realiza un análisis temporal de grano grueso. Para el mismo se agruparon los fechados obtenidos en dos grandes bloques temporales. Uno correspondiente al Holoceno tardío inicial (alrededor de los 3.500 años AP), y otro bloque que comprende el Holoceno tardío final y que agrupa los fechados posteriores a 1.700 años AP. Dentro del primero se analizan las unidades X y XI del área del entierro y las unidades II (base: capa 4), III/IV, V, VII, VIII, IX del sondeo. El bloque más tardío considera la unidad I de ambos sectores (entierro y sondeo) y las capas 2 y 3 de la unidad II del sondeo (ver Tabla 1).

\section{EL ANÁLISIS ARQUEOFAUNÍSTICO}

El conjunto recuperado en OB1 está compuesto por más de 21.600 restos óseos de fauna. El 51\% se recuperó en el sector de la excavación del entierro (L'Heureux y Charlin 2007). Esto tiene importancia, en tanto el 49\% restante procede del sondeo 1 , que representa un área significativamente menor (0,25 vs. $1,50 \mathrm{~m} 2)$. A su vez, el 69,63\% de la fauna recuperada corresponde al Holoceno tardío inicial.

El taxa mejor representado en el sitio son los roedores, con más de 16.000 huesos asignables a 
Tabla 1. Dataciones disponibles para el sitio Orejas de Burro 1

\begin{tabular}{|c|c|c|c|c|c|c|c|}
\hline Procedencia & Unidad & Profundidad & Edad & Técnica & Código & Tipo de Muestra & $\begin{array}{c}\text { Holoceno } \\
\text { tardío }\end{array}$ \\
\hline \multirow{4}{*}{ Sondeo 1} & I/II(capa 2,3) & Ca. $25-45 \mathrm{~cm}$ & $620 \pm 200$ & ${ }^{14} \mathrm{C}$ & AC-1735 & Mytilus sp. & \multirow{4}{*}{$\begin{array}{c}\text { Final: } \\
\text { Post } 1.700\end{array}$} \\
\hline & I/II(capa 2,3) & Ca. $25-45 \mathrm{~cm}$ & $490 \pm 130$ & ${ }^{14} \mathrm{C}$ & AC-1736 & Mytilus sp. & \\
\hline & II (capa 2,3) & $33-37 \mathrm{~cm}$ & $1.760 \pm 70$ & ${ }^{14} \mathrm{C}$ & LP-1462 & carbón vegetal & \\
\hline & II (capa 4) & $46-50 \mathrm{~cm}$ & $3.490 \pm 50$ & AMS & Ua-21901 & óseo guanaco & \\
\hline \multirow{2}{*}{$\begin{array}{c}\text { Estructura de } \\
\text { Entierro }\end{array}$} & $\mathrm{X}$ & $67 \mathrm{~cm}$ & $3.490 \pm 75$ & ${ }^{14} \mathrm{C}$ & LP-1681 & óseo guanaco & \multirow{2}{*}{$\begin{array}{c}\text { Inicial: } \\
\text { Ca. } 3.500\end{array}$} \\
\hline & $\mathrm{XI}$ & $70 \mathrm{~cm}$ & $3.565 \pm 45$ & AMS & Ua-23097 & óseo humano & \\
\hline
\end{tabular}

Ctenomys sp. (Tabla 2). Estos fueron abundantes en todas las unidades y cuadrículas, y tienen una mayor representación en el sector del sondeo 1 (56,36\%) hacia el Holoceno tardío inicial (63,48\%). La abundante presencia de marcas de roedores en los huesos humanos y en la fauna de todos los niveles muestra la intensa actividad generada por los roedores en la historia postdepositacional del conjunto. Se considera la presencia de estos roedores como una incorporación natural. Esto se corrobora con la detección de cuevas durante la excavación (pe. nivel $\mathrm{V}$ del sondeo) y nidos en superficie. Otra forma de ingreso de este taxón a los niveles estratigráficos se relaciona con la abundante presencia de bolos de regurgitación de strigiformes con diferentes estados de integridad en la unidad del relleno (40 enteros, Fig. 5; 87 fragmentados y otros completamente disgregados). Teniendo en consideración lo planteado, los roedores y los especímenes de lagartijas (recuperados predominantemente en el sondeo 1: 88,76\% y en momentos post 1.700 AP: $87,64 \%)$ no se consideran en el siguiente análisis.

\section{Los Mamíferos}

Entre esta fauna arqueológica predominan los especímenes de guanaco $(81,30 \%$ recuperados en el área del entierro y el $93,26 \%$ procede de las unidades representativas del $\mathrm{H}$. tardío inicial), y en menor proporción se registran mamíferos indeterminados y carnívoros (Tabla 2). El carnívoro mejor representado es Puma concolor, seguido por Dusicyon culpaeus y Dusicyon griseus hallados en su totalidad en el $\mathrm{H}$. tardío inicial. A su vez, el 97,87\% de los carnívoros se recuperó en el área del entierro. La presencia de puma en el registro se fortalece con el hallazgo de excrementos asignables a este taxón.

Tabla 2. Fauna recuperada en Orejas de Burro 1 por sectores espaciales intra-sitio y bloques temporales. Detalle de los diferentes taxa de mamíferos

\begin{tabular}{|c|c|c|c|c|c|c|}
\hline TAXA & Sondeo 1 & Área Entierro & H.tardío inicial & H.tardío final & NISP Total & $\%$ \\
\hline Roedores & 9.199 & 7.123 & 10.361 & 5.961 & 16.322 & 75,29 \\
\hline Mamíferos & 1.262 & 3.811 & 4.554 & 519 & 5.073 & 23,40 \\
\hline Aves & 56 & 103 & 135 & 24 & 159 & 0,73 \\
\hline Peces & 3 & 17 & 19 & 1 & 20 & 0,09 \\
\hline Lagartijas & 79 & 10 & 11 & 78 & 89 & 0,41 \\
\hline Indeterminados & 2 & 14 & 15 & 1 & 16 & 0,07 \\
\hline TOTAL & 10.601 & 11.078 & 15.095 & 6.584 & 21.679 & 100 \\
\hline \multicolumn{7}{|l|}{ MAMÍFEROS } \\
\hline Lama guanicoe & 702 & 3.053 & 3.502 & 253 & 3.755 & 74,02 \\
\hline Mamíferos indet. & 557 & 620 & 911 & 266 & 1.177 & 23,20 \\
\hline Carnívoros indet. & 1 & 56 & 57 & 0 & 57 & 1,12 \\
\hline Puma concolor & 0 & 55 & 55 & 0 & 55 & 1,08 \\
\hline Dusicyon culpaeus & 2 & 23 & 25 & 0 & 25 & 0,49 \\
\hline Dusicyon griseus & 0 & 4 & 4 & 0 & 4 & 0,08 \\
\hline TOTAL & 1.262 & 3.811 & 4.554 & 519 & 5.073 & 100 \\
\hline
\end{tabular}




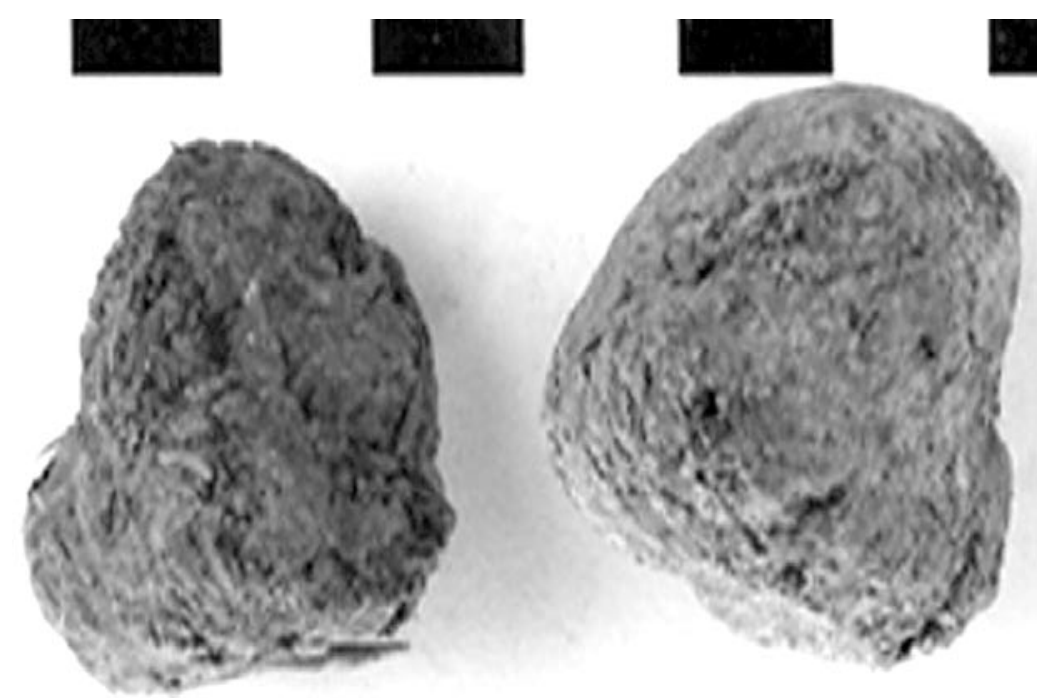

Fig. 5. Es muy abundante la presencia de egagrópilas de aves Strigiformes en el sitio, principalmente en la unidad de relleno (unidad X) del sector del entierro.

Las modificaciones antrópicas de explotación y consumo son elevadas en los huesos de guanaco (Fig. 6a). Se registraron significativamente más frecuencias de huellas y fracturas antrópicas en el área del entierro, $\chi^{2}(\mathrm{P}>0,01)$. Entre bloques temporales las diferencias en las frecuencias de huellas fueron estadísticamente más significativas en el $\mathrm{H}$. tardío inicial, pero no las fracturas de naturaleza antrópica. Por otra parte, se observó una mayor representación de elementos de mamíferos juveniles en el sector del entierro (unidades X y XI), y de especímenes de guanaco y de carnívoros con ocre en la unidad XI del sector del entierro.

Entre los restos de carnívoros se identificó una moderada frecuencia de huellas y fracturas antrópicas, siendo éstas significativamente más elevadas en las unidades del $\mathrm{H}$. tardío inicial del área del entierro $\chi^{2}(\mathrm{P}>0,01$; Fig. 6b). Las fracturas antrópicas longitudinales en huesos largos de $\mathrm{Pu}$ ma concolor y Dusicyon culpaeus evidencian que, además del reconocido uso de dichas especies para la explotación de sus pieles, éstas también fueron procesadas y las médulas óseas consumidas (Fig. 7). El patron de procesamiento registrado resulta similar al observado en los elementos de guanaco.

Entre los especímenes de mamíferos se destaca el hallazgo de cuatro cuentas óseas (pulidas y con huellas) confeccionadas sobre segmentos de diáfisis de hueso largo de un mamífero grande (Fig. 8). Tres de éstas se recuperaron en la unidad X por sobre las rocas que cubrían el entierro. La cuarta cuenta, teñida con ocre en su cara interna, se halló junto con otros huesos humanos -que no se relacionan con los esqueletos del entierro- en la parte superior de este relleno. A su vez, en esta misma unidad se recuperaron cuatro instrumentos confeccionados sobre huesos largos de guanaco: dos retocadores y dos intrumentos indeterminados, y abundantes epífisis con fractura transversal y características semejantes a las atribuidas por Hajduk y Lezcano (2005) a los "machacadores" óseos (pe. negativos de lascados laterales y contiguos en el plano de fractura, etc.). Por otra parte, en la cueva de roedores detectada en el sondeo 1 se halló un instrumento con decoración incisa realizado sobre un metatarso de guanaco (Fig. 9).

La fragmentación pre y posdepositacional entre los especímenes es significativamente mayor en el conjunto del sondeo 1 (Mann-Whitney U test; $\mathrm{P}>0,01$ ), con más del 50\% de los fragmentos entre 0 y $2 \mathrm{~cm}$. Por el contrario, en el área del entierro predominaron los tamaños entre 2 y $4 \mathrm{~cm}$, y se registran segmentos de huesos de hasta $19 \mathrm{~cm}$ (Fig. 10). Este mismo patrón se observa entre los bloques temporales, registrándose una diferencia significativa con una fragmentación mayor para el Holoceno tardío final (Mann-Whitney U test; P > 0,01; Fig. 10).

El análisis de las modificaciones tafonómicas mostró una muy baja meteorización entre los especímenes de mamíferos en todo el sitio (estadio 0: 


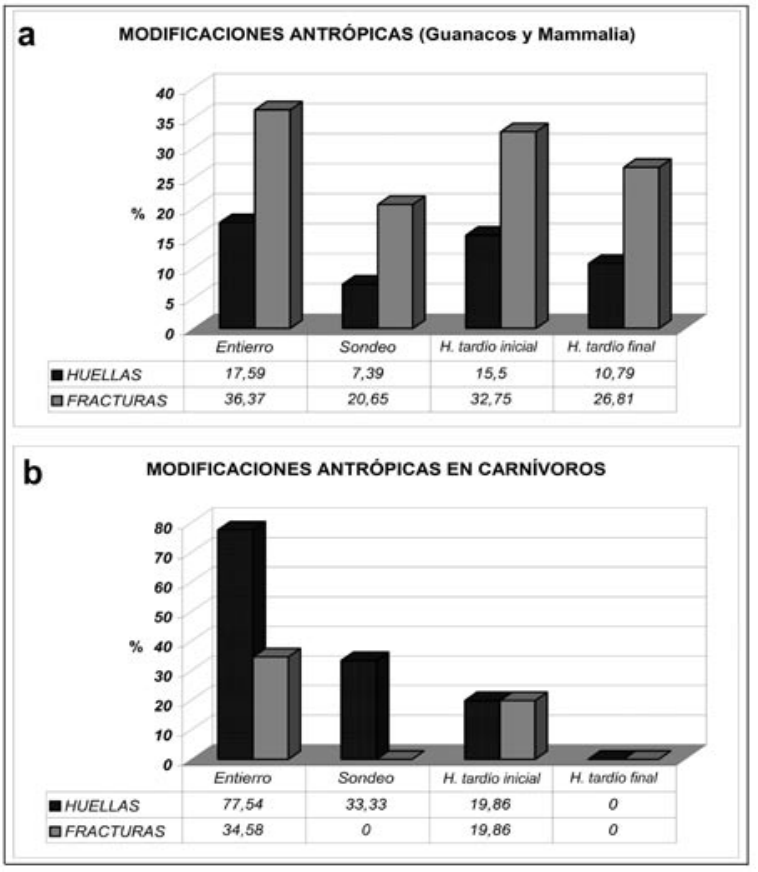

Fig. 6. Frecuencia de modificaciones antrópicas entre los especímenes de: a) guanaco y otros mamíferos indeterminados y b) de carnívoros.

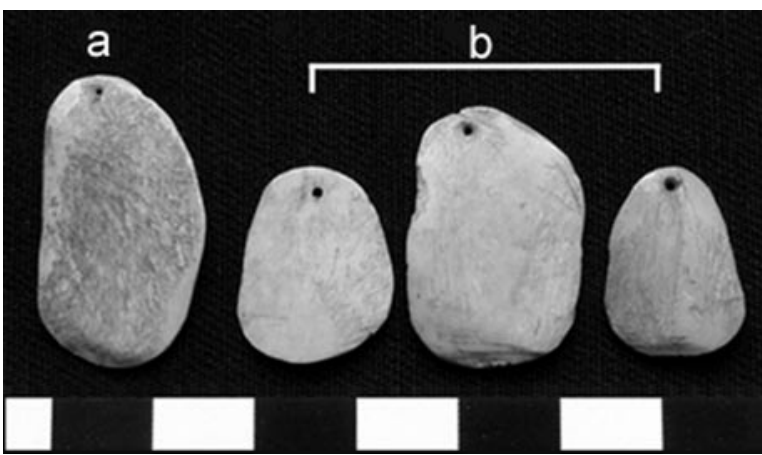

Fig. 8. Las cuentas óseas de fauna recuperadas en el relleno: a): cuenta con ocre en su cara interna hallada a $37 \mathrm{~cm}$ de profundidad (unidad X); b): cuentas halladas sobre los bloques que cubrían el entierro.

$81,70 \%$ en el sector del entierro y $75 \%$ en el sondeo; escala de Behrensmeyer 1978). Es llamativo observar el mismo perfil de meteorización en ambos sectores excavados y bloques temporales (Fig. 11). Los numerosos casos de meteorización indeterminada en el sondeo en los niveles correspondientes al 3.500 años AP del sondeo, se relacionan con la presencia significativamente mayor de huesos con alteración térmica en ese sector y bloque temporal $\left(\chi^{2}, \mathrm{P}<0,01\right.$; Fig. 11). Esto último resulta coherente con el abundante

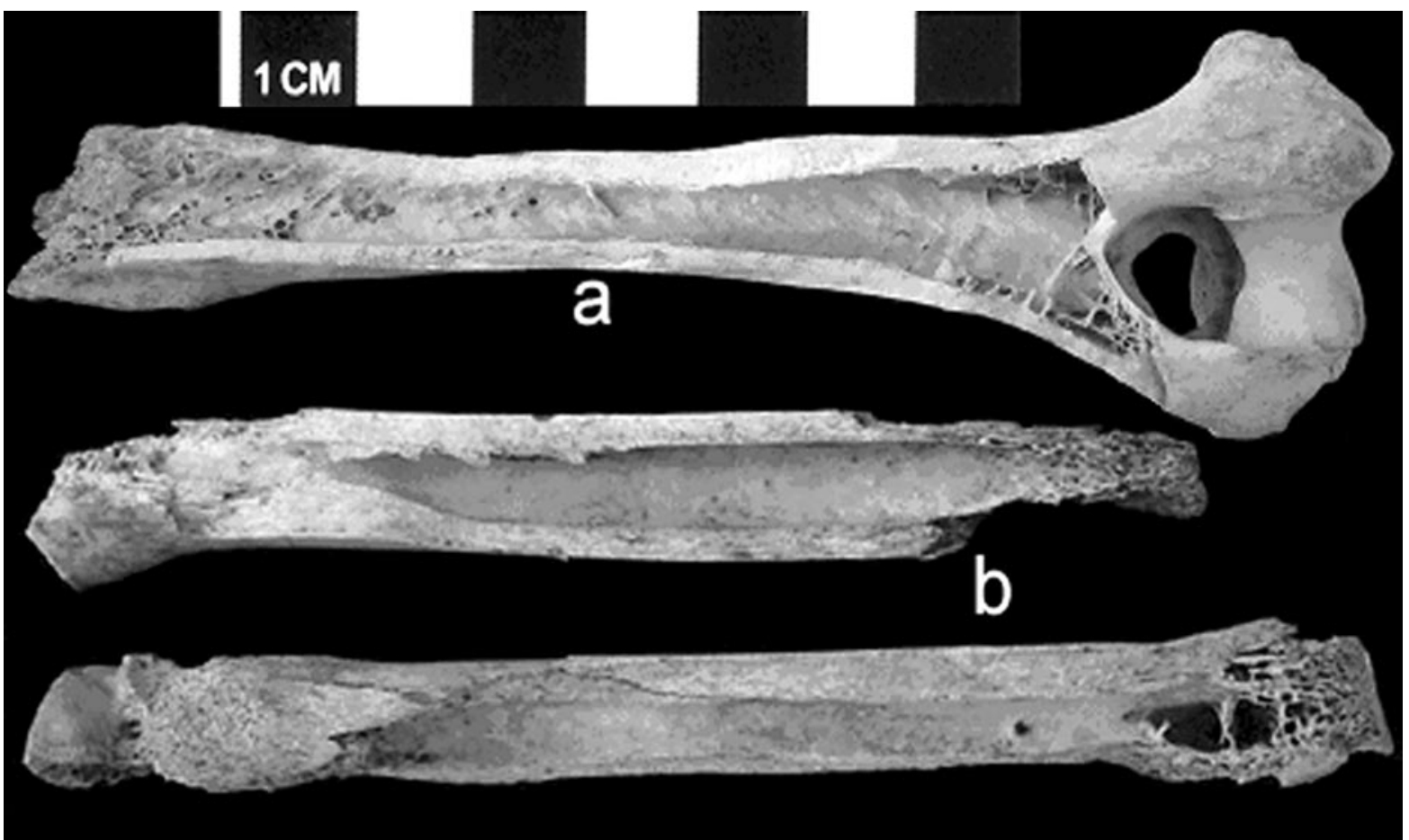

Fig. 7. Evidencia de consumo de médula ósea en huesos largos de carnívoros. Fracturas antrópicas longitudinales y lascados en: a) húmero izquierdo de zorro colorado, y b) metapodios de puma. 


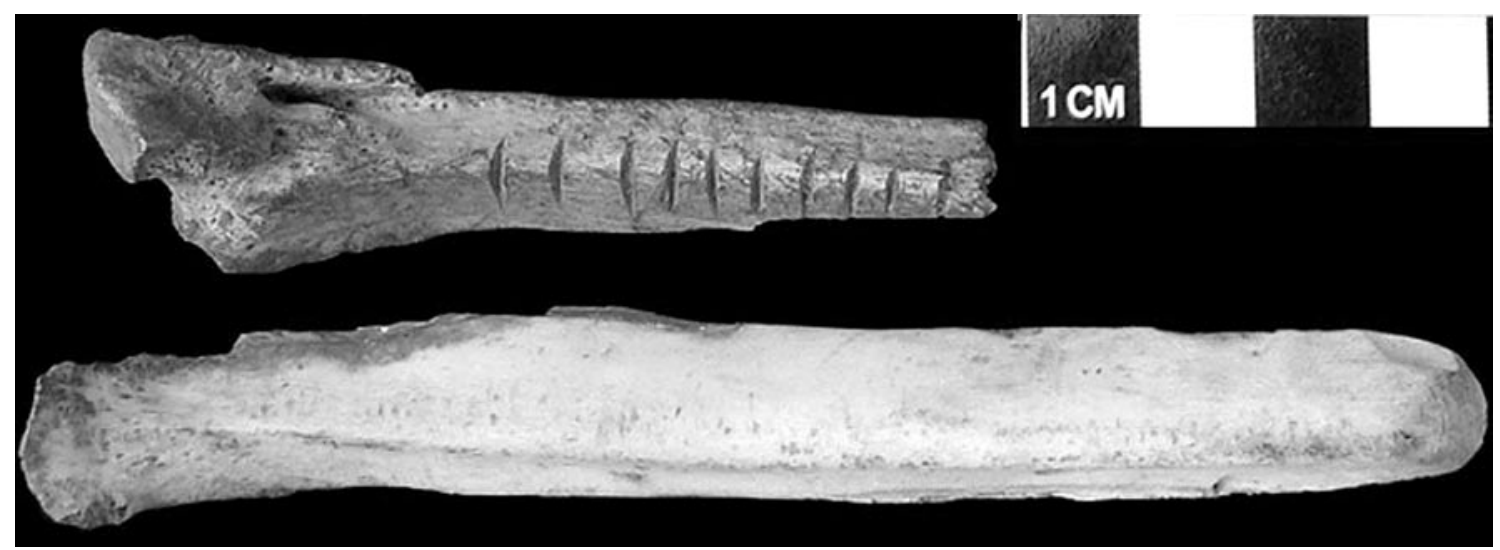

Fig. 9. Instrumentos óseos confeccionados en elementos de guanaco. Retocador en diáfisis de metacarpo izquierdo y un instrumento fracturado con decorado inciso (paralelo) confeccionado sobre metatarso izquierdo

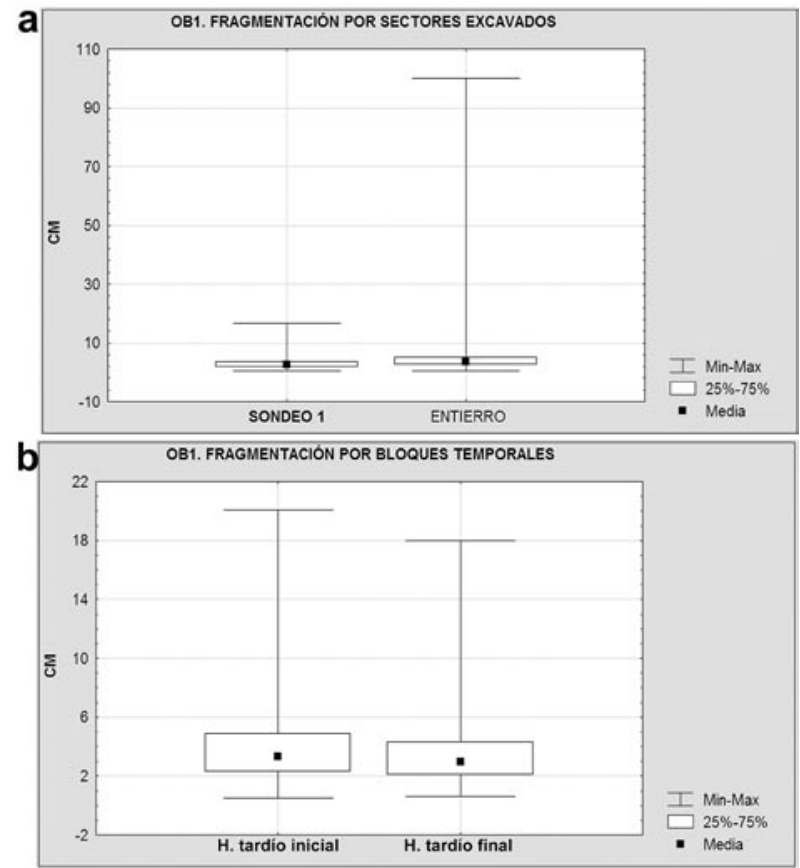

Fig. 10. Fragmentación y rangos de tamaños representados en los especímenes de mamíferos: a) por sectores excavados; b) por bloques temporales.

registro de partículas de carbón en las unidades II, III y VIII del sondeo, y la presencia de un rasgo de origen antrópico correspondiente a un lente bien definida de carbones y cenizas en la unidad III.

Por otro lado, se observa una serie de modificaciones postdepositacionales estadísticamente más representadas en el sector del entierro y el Holoceno tardío inicial, que no son relevantes entre los huesos recuperados en el sondeo después del
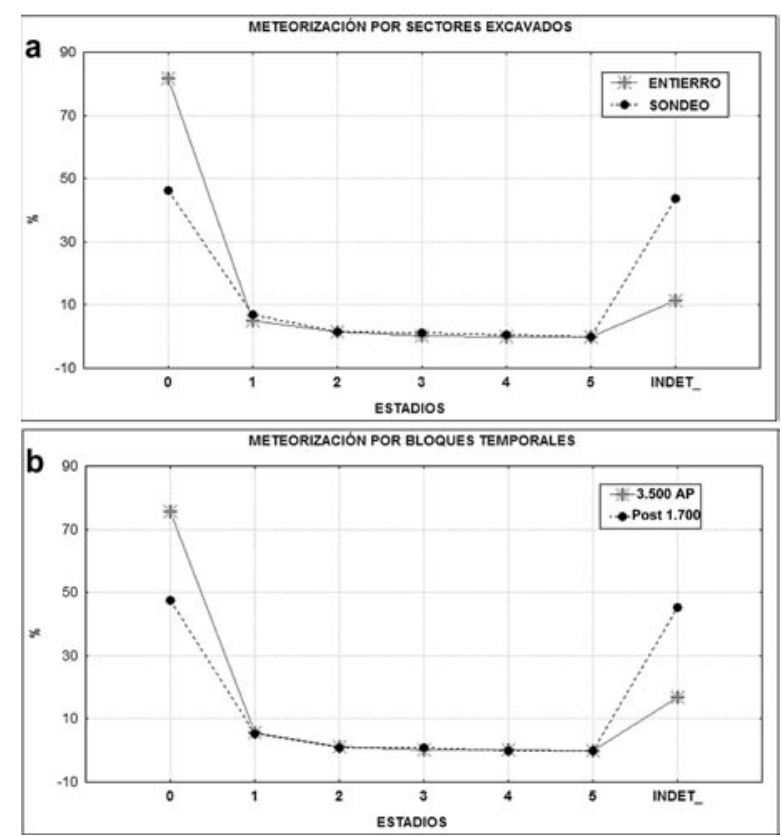

Figura 11. Perfiles de meteorización: a) por sectores excavados; b) por bloques temporales.

1.700 años AP, como la mayor presencia de huesos teñidos con manganeso, marcas de roedores $y$ exfoliación ( $\chi^{2}, \mathrm{P}<0,01$; Fig. 12). La presencia de daños mecánicos registra una diferencia estadística para los mismos grupos pero con una signifcancia menor $\left(\chi^{2}, \mathrm{P}<0,05\right)$. Se entiende que estos daños se produjeron por el contacto de las aristas de las rocas de basalto de incorporación endógena que formaban parte de la unidad $\mathrm{X}$ del relleno con las superficies corticales de los huesos, en forma 
combinada con la actividad de pisoteo generada tanto por agentes antrópicos como naturales. Estos daños mecánicos se presentan de forma variable, en su mayoría como pits acompañados de estrías y fisuras radiales, y en ocasiones con el hundimiento del tejido cortical (Fig. 13). Tales daños mecánicos fueron significativamente mayores entre los huesos humanos debido a que los cuerpos fueron cubiertos directamente con grandes bloques de roca de caja (L'Heureux y Barberena 2008). Por otro lado, la presencia de $\mathrm{CaCO} 3$ en los especímenes de fauna de la unidad $\mathrm{X}$, se relaciona con los nódulos de carbonato hallados tanto en los sedimentos de esta unidad (Fig. 4) como en las unidades VII, VI, V del sector del entierro y II del sondeo.

\section{La Avifauna}

Comparativamente con otros sitios del área, en OB1 es muy abundante y variada la representación de restos de aves. Los especímenes se hallaron, al igual que otros taxa, significativamente más representados en el relleno del sector del entierro $(64,78 \%)$ durante el Holoceno tardío inicial $(84,91 \%)\left(\chi^{2}, \mathrm{P}\right.$ $<0,01$; Tabla 3).

Del conjunto avifaunístico sólo se pudo determinar el 37,74\% de especímenes. Las aves identificadas mejor representadas pertenecen a la familia de las Falconiformes (21,38\%), y entre ellas el águila mora (Geranoaetus melanoleucus). Le siguen en frecuencia los especímenes del Orden Charadriiformes (7,55\%), entre los que se registraron

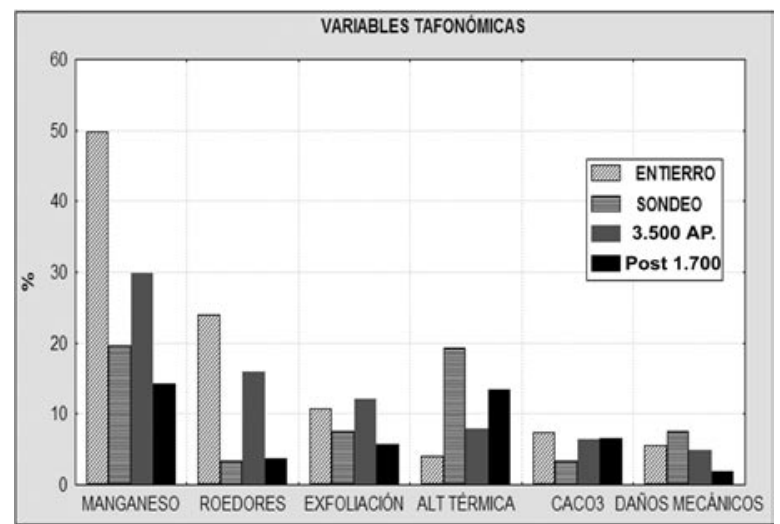

Fig.12. Variables tafonómicas. Proporciones de: tinción con manganeso; actividad de roedores; exfoliación; alteración térmica; carbonato de calcio y daños mecánicos en los especímenes de mamíferos. algunos elementos de aves costeras como Larus dominicanus. Dentro de estos taxa hay especímenes que no pudieron ser identificados a nivel de género o especie, pero se considera que los mismos podrían representar diferentes tipos de aves pequeñas pertenecientes a este Orden (pe. ostreros, chorlos, playeritos, etc.) muy frecuentes en toda la costa del estrecho de Magallanes (Tabla 3).

Por otro lado, se reconocieron pocos especímenes de Strigiformes (Tyto alba -lechuza-; todos en el relleno), de cauquén (Chloephaga sp.) y otras aves costeras como cormorán (Phalacrocorax sp.) y marinas: albatros (Diomedea sp.). La presencia de Strigiformes en el sitio está mejor definida por las numerosas egagrópilas enteras o fragmentadas halladas en la unidad del relleno (Fig. 5).

Es importante mencionar el hallazgo de tres punzones de huesos de aves, uno confeccionado sobre un cúbito de albatros que presenta decoración incisa (paralela y oblícua) y restos de ocre en su interior, otro punzón realizado en una tibiatarso de cormorán, igualmente decorado (incisiones paralelas y borde denticulado) y un tercero sobre un húmero de ave indeterminada (Fig. 14). Todos fueron hallados en el límite de las unidades X y XI, por sobre y entre las rocas que cubrían el entierro, por lo que no se encontraban en asociación directa con los esqueletos.

$\mathrm{Al}$ igual que fuera observado entre los especímenes de carnívoros, en el conjunto aves se registra una moderada frecuencia de huellas $(13,49 \%)$ y fracturas antrópicas $(3,72 \%)$, donde el mayor por-

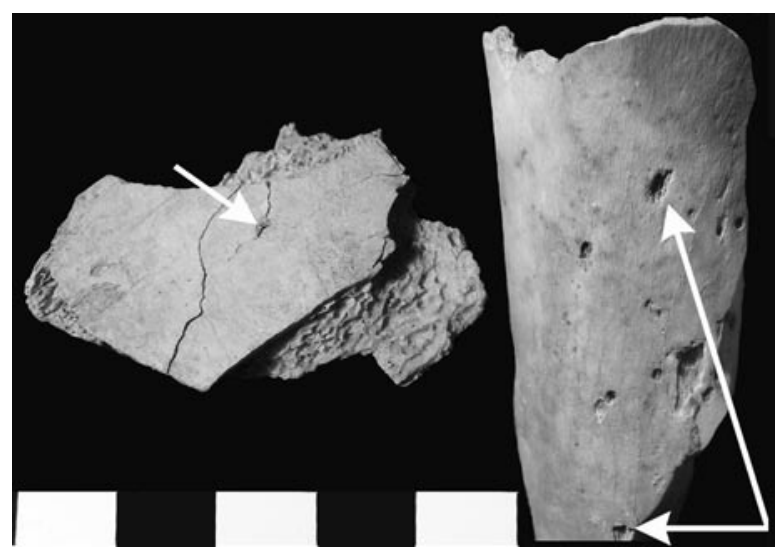

Fig. 13. Daños mecánicos registrados en las superficies corticales de los huesos de guanaco. Se observan pits en un splinter de húmero y hundimiento de tejido cortical con fisuras en un fragmento de pelvis. 


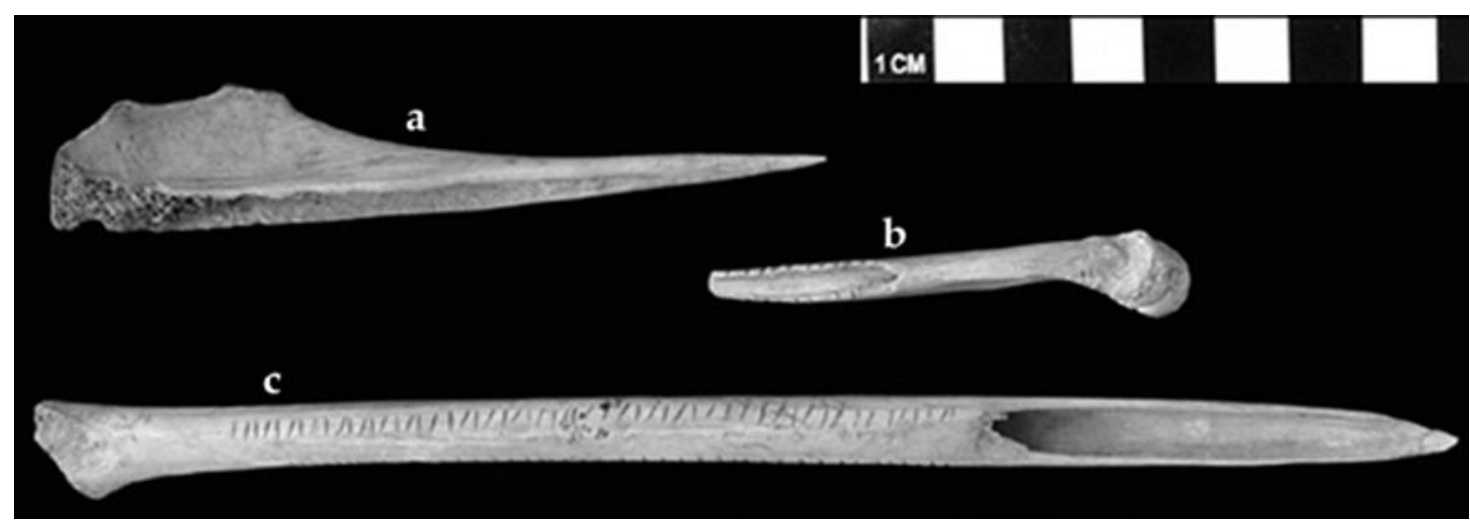

Fig. 14. Instrumentos óseos confeccionados sobre huesos de aves, a): punzón con huellas en un húmero de ave indeterminada; b): punzón con decoración incisa en una tibiatarso de cormorán, y c): punzón realizado sobre un cubito de albatros con decoración incisa paralela y oblicua y abundante ocre en su interior.

centaje de tales modificaciones se registra entre los especímenes de Falconiformes identificados en el área del entierro hacia el $\mathrm{H}$. tardío inicial (ca. 3.500 años AP; Fig. 15). Esto tiene relevancia en tanto no se conocen otros contextos regionales con evidencias de procesamiento de aves rapaces diurnas carroñeras y/o cazadoras.

\section{Los Moluscos}

Un tema a desarrollar es la importante presencia de restos de moluscos en el sitio (Fig. 16). En la superficie de la entrada de la cueva se observaron abundantes valvas integrando los montículos de sedimento que fueron interpretados como aquellos removidos durante las excavaciones de Guerra de Fretes (1977). Igualmente, en la excavación se recuperaron gran cantidad de ellos, estando principalmente representados en este conjunto los mejillones (Mytilus sp.), las cholgas (Aulacomya sp.) y en menor proporción las lapas [Nacella (Patinigera) sp.]. En todos los géneros la presencia de moluscos fue significativamente mayor en la unidad del relleno del entierro asignada al $\mathrm{H}$. tardío inicial $\left(\chi^{2}, \mathrm{P}<0,01\right)$. En la Tabla 4 se presenta solamente la cuantificación de los moluscos recuperados en estratigrafía que conservaban las charnelas enteras.

Las valvas no registran rastros de formatiza-

Tabla 3. Avifauna presente en el sitio OB1. Frecuencias por sectores excavados y bloques temporales.

\begin{tabular}{|c|c|c|c|c|c|c|}
\hline AVES & Sondeo 1 & $\begin{array}{c}\text { Área } \\
\text { Entierro }\end{array}$ & $\begin{array}{c}\text { H. tardío } \\
\text { inicial }\end{array}$ & $\begin{array}{c}\text { H. tardío } \\
\text { final }\end{array}$ & NISP Total & $\%$ \\
\hline Geranoaetus melanoleucus & 0 & 17 & 17 & 0 & 17 & 10,69 \\
\hline Polyborus australis & 0 & 4 & 4 & 0 & 4 & 2,52 \\
\hline Vanellus chilensis (C) & 0 & 3 & 3 & 0 & 3 & 1,89 \\
\hline Larus dominicanus (M) & 0 & 2 & 2 & 0 & 2 & 1,26 \\
\hline Tyto alba & 0 & 3 & 3 & 0 & 3 & 1,89 \\
\hline Chloephaga sp. & 0 & 3 & 3 & 0 & 3 & 1,89 \\
\hline Phalacrocorax sp. (C) & 0 & 2 & 2 & 0 & 2 & 1,26 \\
\hline Diomedea sp. (M) & 0 & 1 & 1 & 0 & 1 & 0,63 \\
\hline Falconiformes & 2 & 11 & 13 & 0 & 13 & 8,18 \\
\hline Charadriiformes (*) & 5 & 2 & 6 & 1 & 7 & 4,40 \\
\hline Ciconiiformes & 0 & 4 & 4 & 0 & 4 & 2,52 \\
\hline Strigiformes & 0 & 1 & 1 & 0 & 1 & 0,63 \\
\hline Aves indeterminadas & 49 & 50 & 76 & 23 & 99 & 62,27 \\
\hline TOTAL & 56 & 103 & 135 & 24 & 159 & 100 \\
\hline
\end{tabular}

C: Aves de ambiente costero; M: Aves marinas; ": otras aves del Orden Charadriiformes que se asocian con diferentes especies de aves costeras del área (pe. ostreros, chorlos, playeritos) 


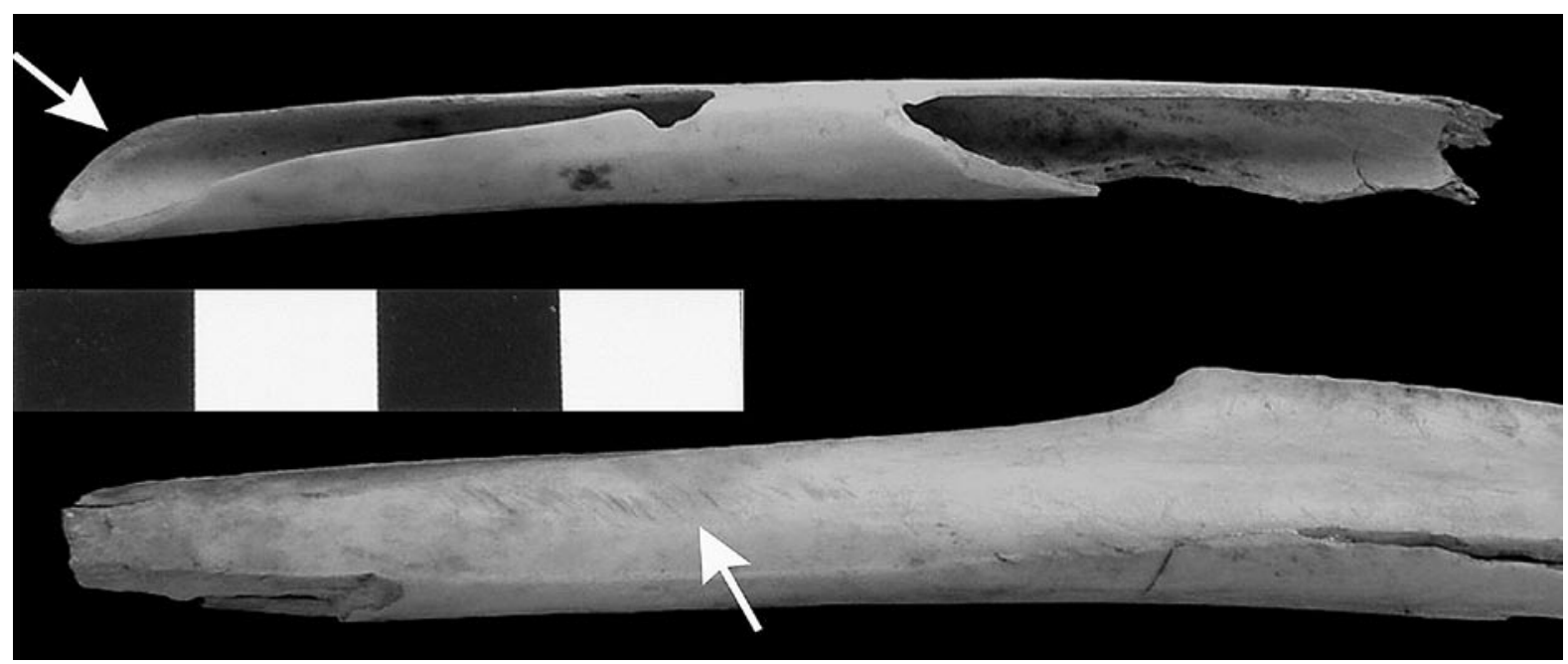

Fig. 15. Modificaciones antrópicas en los especimenes de aves. Fracturas (transversal y longitudinal) y huellas en tibiastarso de Geranoaetus melanoleucus.

ción o decorado, por lo que se considera que los moluscos fueron recolectados para su consumo. Por otro lado, se recuperaron dos especímenes de balánidos en los niveles del Holoceno tardío inicial del área del sondeo. Estos gasterópodos parásitos de agua fría, que se encuentran usualmente adheridos a superficies duras como rocas o valvas, se pueden asociar con el transporte de ristras de valvas desde la costa.

Una mención aparte se merecen los especímenes de peces, el taxón menos representado, los cuales no pudieron ser identificados a nivel de género o familia. Por lo tanto no se conoce con certeza si se trata de peces de agua dulce o salada. Pero, por otro lado, se conoce que en la fuente de agua dulce más cercana: la laguna Azul, localizada a $10 \mathrm{~km}$ en dirección NW, no hay vida ictícola. Entonces, la probabilidad que procedan de la costa marina del Estrecho, a $17 \mathrm{~km}$ del sitio, es alta en comparación con otras potenciales fuentes de aprovisionamiento de peces de agua dulce en la región, a saber los ríos Gallegos (ca. 51,7 km) o Chico (ca. 18,5 km). El 95\% de los huesos de peces se hallaron en unidades del Holoceno tardío inicial y el 85\% procede del área del entierro.

\section{DISCUSIÓN}

Evidencia espacial intrasitio

OB1 es un sitio multifuncional en el que se ha registrado, entre otras evidencias de uso (lentes de fogones, consumo de alimentos, formatización de intrumentos), su reutilización como sector de entierro (por lo menos dos eventos de inhumación) (Franco et al. en prep.; L'Heureux y Barberena 2008). En este sitio el $85 \%$ de la superficie excavada representa el area de entierro que, por sus características particulares, no fue analizada conjuntamente con las muestras de sectores colindantes (igual tratamiento en L'Heureux y Charlin 2007). De acuerdo con los resultados obtenidos, los conjuntos faunísticos del área del entierro y del sondeo mostraron un comportamiento estadístico significativamente diferente, lo cual justifica su

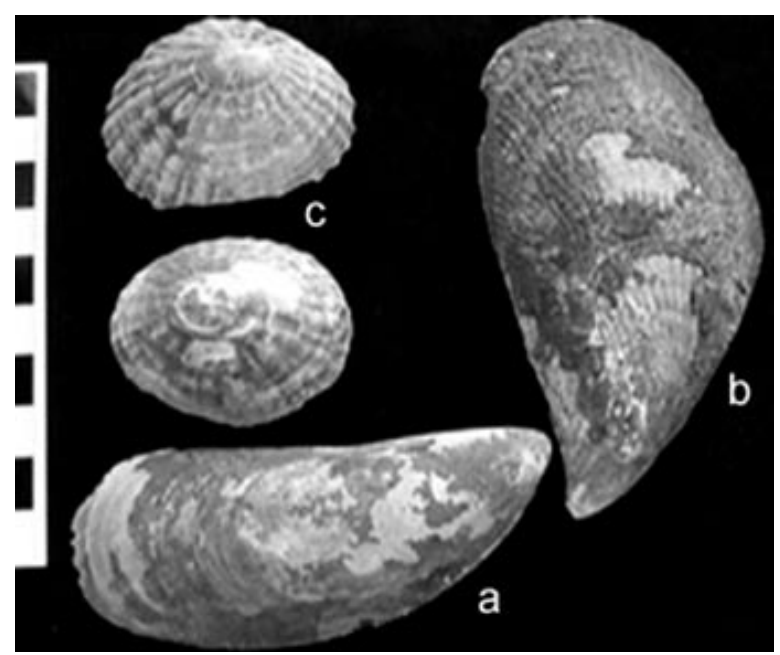

Fig. 16. Los géneros de moluscos hallados en la cueva: a) Mytilus sp.; b) Aulacomya ater y c) Nacella (Patinigera) sp. 
Tabla 4. Restos malacológicos hallados en Orejas de Burro 1

\begin{tabular}{|c|c|c|c|c|c|c|}
\hline $\begin{array}{c}\text { MOLUSCOS } \\
\text { (enteros o c /charnela) }\end{array}$ & Sondeo 1 & Área Entierro & H.tardío inicial & H.tardío final & NISP Total & $\%$ \\
\hline Mytilus sp. & 168 & 829 & 836 & 161 & 997 & 97,36 \\
\hline Aulacomya ater & 2 & 17 & 17 & 2 & 19 & 1,86 \\
\hline Nacella (Patinígera) sp. & 1 & 7 & 7 & 1 & 8 & 0,08 \\
\hline TOTAL & 171 & 853 & 860 & 164 & 1.024 & 100 \\
\hline
\end{tabular}

tratamiento separado.

Independientemente de los diferentes tamaños muestrales, la mayor diversidad de taxa y frecuencias de especímenes por categorías se hallaron en el sector del entierro (pe. aves y carnívoros). Lo mismo se registró para la mayoría de las variables antrópicas o tafonómicas analizadas, con excepción de la mayor fragmentación y las frecuencias de alteración térmica, que resultaron significativamente más representadas en el sector del sondeo. Esto último también pudo ser observado entre los escasos artefactos líticos hallados en el sitio, los cuales mostraron una mayor fragmentación y tamaños más pequeños en el sondeo 1 (Charlin 2008).

\section{Tendencia temporal}

En principio hay que mencionar que los bloques temporales utilizados representan una segmentación arbitraria que puede limitar la variabilidad intra-grupal existente, pero que, de acuerdo con los fechados disponibles, resulta la única posible para realizar una aproximación temporal dentro del Holoceno tardío. De todos modos, es interesante destacar los resultados generados desde esta perspectiva.

La mayor parte de la evidencia arqueofaunística analizada corresponde a los momentos tempranos del Holoceno tardío, lo cual marca una diferencia estadística en todos los taxa representados respecto del bloque del Holoceno tardío final.

Las modificaciones antrópicas de especímenes de mamíferos muestran una significativa representación en el sector del entierro alrededor del 3.500 años AP. Tanto los retocadores como las cuentas óseas encontradas en el sitio se asemejan a aquellos instrumentos y ornamentos hallados por J. Bird en las cuevas Cañadón Leona, Pali Aike y Fell, adjudicados por el autor al Período IV de su secuencia cronológica con una edad análoga (Período IV: 3.500 años AP - presente; Fig. 15 en Bird 1988). Esta semejanza con OB1 plantearía un comportamiento regional extendido en los patrones óseos tecnológicos a comienzos del Holoceno tardío que deberá ser evaluado a futuro.

Todas las variables tafonómicas registraron una mayor y significativa representación en el Holoceno tardío inicial (a excepción de la presencia de especímenes con alteración térmica que muestra un patrón opuesto). También la evidencia de procesamiento de aves rapaces y de carnívoros grandes. Esto último, más allá del momento temporal asignado, resulta destacable teniendo en cuenta los escasos casos arquelógicos registrados de consumo de aves cazadoras/carroñeras y de carnívoros medianos y grandes.

En suma, la secuencia cronológica obtenida en el sitio apunta al uso redundante de la cueva durante todo el Holoceno tardío, aunque, a partir del análisis de la fauna, puede sostenerse una mayor intensidad en su uso alrrededor de los 3.500 años AP. En este sentido, el análisis lítico (Charlin 2008) y bioarqueológico (L'Heureux y Barberena 2008) muestra tendencias semejantes.

\section{Perspectiva regional}

A partir del estudio de la arqueofauna del sitio se cuenta con un cuerpo de información relevante que avala un patrón de movilidad que incluye la interacción periódica de los grupos cazadores del interior con el mar. Hay que mencionar que la costa marina más cercana es, en línea recta, la del estrecho de Magallanes, que se encuentra a $17 \mathrm{~km}$ del sitio.

OB1 da cuenta de la existencia de una circulación de diferentes ítems marinos/costeros hacia el interior del continente. Del estrecho de Magallanes provendrían los abundantes moluscos descartados y los restos de aves marinas y costeras formatizados y decorados, como probablemente también la macrofauna invertebrada asociada (balánidos) y los restos de peces aún no determinados. Las elevadas 
frecuencias en que se hallan los moluscos denota que esta circulación fue reiterada y continua durante todo el Holoceno tardío. Se ha planteado que estos movimientos fueron realizados por los cazadores del área dentro de movimientos logísticos habituales desde el interior hacia la costa (Borrero y Barberena 2006). También que la explotación de los moluscos incrementó durante los últimos milenios (Barberena 2008), no obstante, hay que mencionar que la tasa de descarte de valvas estudiada fue significativamente más elevada en los niveles correspondientes al Holoceno tardío inicial $\left(\chi^{2}, \mathrm{P}<0,01\right)$. Igualmente, tal relación no resulta muy clara si se tiene en cuenta que los moluscos en el sondeo fueron datados en momentos muy tardíos, lo que podría estar alertando sobre la probable acción de migración vertical y/o mezcla de valvas en el relleno. Pero, por otro lado, para comienzos del Holoceno se registra la presencia de otras evidencias faunísticas y bioarqueológicas (valores $\delta{ }^{13} \mathrm{C}$ y $\delta{ }^{15} \mathrm{~N}$ en dos de los esqueletos del entierro; Barberena 2008; L'Heureux y Barberena 2008) que avalan la vinculación del sitio con la costa marina del Estrecho y el consumo de alimentos marinos hacia el 3.500 años AP. De acuerdo con esto, se puede sostener la explotación de moluscos y otros recursos marinos desde comienzos del Holoceno tardío, y considerar los restos de valvas y parásitos hallados en momentos posteriores al 1.700 años AP, como la continuidad en el uso y explotación de los diferentes espacios costeros para el Holoceno tardío final.

Para finalizar, se considera la presencia de una jerarquización en la selección de estos espacios para la obtención de los diferentes recursos de acuerdo con la disponibilidad de los mismos y de las distancias que los involucran (pe. Estrecho: 17 km vs. Atlántico: $70 \mathrm{~km}$ y río Gallegos: $51 \mathrm{~km}$ ). En este sentido se observa que la obtención de recursos faunísticos alimenticios, ornamentales o instrumentales, estuvo acotado a un rango espacial menor a los $20 \mathrm{~km}$, siendo la costa del Estrecho el ambiente que brindó la mayor variabilidad de especies representadas en el sitio, principalmente a comienzos del Holoceno tardío.

\section{AGRADECIMIENTOS}

A mis compañeros de equipo: Nora Franco, Ramiro Barberena y Judith Charlin, por su gran ayuda durante los trabajos de campo y posteriores estudios. Al Dr. Esteban Perazzo, la Compañía de Tierras del Sud y todo el personal de la estancia Monte Aymond por su colaboración.

A Claudia Tambussi (FCNyM, UNLP), por facilitarnos las colecciones de aves para la identificación del material avifaunístico. A Néstor Landoni (Museo de Ciencias Naturales Bernardino Rivadavia) y a Patricia Campán por la identificación de las especies de moluscos.

Este trabajo se desarrolló en el marco de los proyectos: Magallania III (PIP № 2390), Modos de interacción entre poblaciones humanas de Patagonia meridional (PICT № 04-09498), Hunter-Gatherer archaeology and palaeoecological research at the Pali-Aike lava field (NG Research Grant № 773604) y Circulación Humana en el extremo Sur de la Patagonia (UBACyT F133) dirigidos por el Dr. Luis A. Borrero.

\section{BIBLIOGRAFÍA}

BARBERENA, R. 2008. Arqueología y biogeografía humana en Patagonia meridional. Sociedad Argentina de Antropología, Buenos Aires.

BARBERENA, R., A. BLASI y C. CASTIÑEIRA. 2006. Geoarqueología en cuevas: el sitio Orejas de Burro 1 (Pali Aike, Argentina). Magallania 34(1):119-138, Punta Arenas.

BEHRENSMEYER, A. K. 1978. Taphonomic and ecologic information from bone weathering. Paleobiology 4:150-162.

BIRD, J. 1988. Travels and archaeology in South Chile. Editado por J. Hyslop. University of Iowa Press.

BORRERO, L. A., L. MANZI, G. L. L'HEUREUX, F. MARTIN, N.V. FRANCO, J. CHARLIN, R. BARBERENA y P. CAMPAN. 2004. Arqueología del Campo de lava Pali Aike, Argentina. Resúmenes del XV Congreso Nacional de Arqueología Argentina, pp. 368. Universidad Nacional de Río Cuarto.

BORRERO, L. A. y R. BARBERENA. 2006. Hunter-Gatherer home ranges and marine resources. An archaeological case from southern Patagonia. Current Anthropology 47:855-867.

CORDERO, R., H. O. PANARELLO, S. LANZELOTTI y C. M. FAVIER DUBOIS. 2003. Radiocarbon age offsets between living organisms from the marine and continental reservoir in coastal localities of Patagonia (Argentina). Radiocarbon 45 (1): 9-15. 
D'ORAZIO, M., S. AGOSTINI, F. MAZZARINI, F. INNOCENTI, P. MANETTI, M. J. ALLER y A. LAHSEN. 2000. The Pali Aike volcanic Field, Patagonia: Slab-Window Magmatism near the Tip of South America. Tectonophysics 321:407-427.

CHARLIN, J. 2008. Estrategias de aprovisionamiento y utilización de las materias primas líticas en el Campo Volcánico Pali Aike, Santa Cruz, Argentina. Tesis Doctoral inédita, Facultad de Filosofía y Letras, Universidad de Buenos Aires.

FRANCO, N. V., G. L. L'HEUREUX, J. E. CHARLIN y R. BARBERENA. El sitio Orejas de Burro 1 y la arqueología del campo volcánico Pali Aike. Ms. En preparación.

GUERRA DE FRETES, E. 1977. Informe preliminar del hallazgo de restos humanos en una de las cuevas del paraje denominado "Monte Aymond". Actas y Memorias del IV Congreso Nacional de Arqueología Argentina, Revista del Museo de Historia Natural de San Rafael, IV(1/4):101-102, Mendoza

HAJDUK, A. y M. LEZCANO. 2005. Un "nuevo-viejo" integrante del elenco de instrumentos óseos de Patagonia: los machacadores óseos. Magallania 33(1):63-80.

L'HEUREUX, G. L. y R. BARBERENA. 2008. El entierro del sitio Orejas de Burro 1, Campo volcánico Pali Aike. En prensa en Intersecciones en Antropología 8. Olavarría.

L'HEUREUX, G. L. y J. E. CHARLIN. 2007. Análisis lítico y arqueofaunístico del sitio Orejas de Burro 1, Pali Aike, Pcia de Santa Cruz. Actas del XVI Congreso Nacional de Arqueología Argentina, III: 409-415, San Salvador de Jujuy. 